\title{
A APROPRIAÇÃO CAMONIANA NO SÉCULO XXI: GONÇALO M. TAVARES E A ÍNDIA
}

\author{
THE CAMONIAN APPROPRIATION \\ IN THE 21ST CENTURY: \\ GONÇALO M. TAVARES AND INDIA
}

Evelyn Blaut Fernandes ${ }^{1}$

\section{RESUMO}

Partindo do reconhecimento de que a obra de Luís de Camões consiste na pedra angular do cânone literário português, este artigo pretende refletir sobre a relação d'Os lusíadas, enquanto símbolo da própria memória de uma cultura, com Uma viagem à Índia: melancolia contemporânea (um itinerário), de Gonçalo M. Tavares. Desde o destino expresso no título até a repetição da estrutura da epopeia camoniana, o texto do século XXI evidencia a influência da obra quinhentista. Por outro lado, o deslocamento da personagem Bloom em contexto de perseguição e fuga problematiza o épico, enquanto também avança na leitura dialética das contradições do amor. Ao acompanhar o itinerário dessa (contra)epopeia, este artigo procura apontar convergências e divergências entre Uma viagem à Índia e Os lusíadas.

PALAVRAS-CHAVE:Luís de Camões; ficção portuguesa contemporânea; Gonçalo M. Tavares.

\section{ABSTRACT}

Starting from the recognition that Luís de Camões' work is the headstone of Portuguese literary canon, this article intends to think about the relationship of The lusiads, as a symbol of the very memory of a culture, with A trip to India: contemporary melancholy (an itinerary), by Gonçalo M. Tavares. From the fate expressed in the title to the repetition of the structure of the Camonian epic, the 21st century text highlights the influence of the 16 th century work. On the other hand, the displacement of the character Bloom in the context of persecution and escape problematizes the epic, 
while also advancing in the dialectical reading of contradictions of love. Following the itinerary of this (anti)epic, this article seeks to point out convergences and divergences between A trip to India and The lusiads.

KEYWORDS: Luís de Camões; Portuguese contemporaryfiction; Gonçalo M. Tavares.

De qualquer maneira, Bloom, em pleno ar, lembrou-se do mar.

$\left(V I^{2}, \mathrm{~V}, 18\right)$

Tell me about a complicated man. Esta frase parece uma solução bem-sucedida de Emily Wilson, ao traduzir para o inglês o primeiro verso da Odisseia que resultou, por exemplo, na edição brasileira, traduzida por Frederico Lourenço, no verso: "Fala-me, Musa, do homem astuto que tanto vagueou". Recupero a argumentação de Caetano Galindo (2019) para o

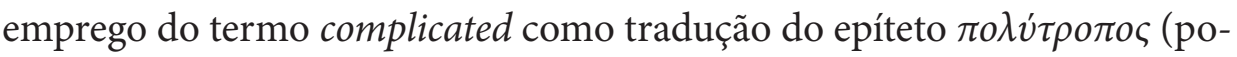
lítropos) "porque 'complicare', em latim, queria dizer mais ou menos 'encher de dobras' (é desse plicare que a gente tira preguear e também plissar [além de chegar, que é outra história]). [...] Ou seja, a tradução de Wilson tem [] um lastro etimológico". Além disso, essa frase aparentemente simples aproxima Ulisses da realidade contemporânea e, neste aspecto, embora $a$ complicated man seja o herói homérico, poderia facilmente referir-se ao "nosso herói" (VI, I, 10 ss.) que vive a realidade complicada do século XXI, de tal modo que Uma viagem à Índia: melancolia contemporânea (um itinerário), de Gonçalo M. Tavares, apresenta condições de ser lida como uma "old story for our modern times" (Homer, 2018, p. 105).

Contudo, importam menos os paralelismos que se podem traçar com a Odisseia, Ulysses, ou mesmo Leaves of grass, do que as escolhas que determinam o intenso diálogo dessa ambiciosa obra de Gonçalo M. Tavares com o seu tempo. A autoria dos poemas em versos hexâmetros compostos entre os séculos VIII a.C. e VII a.C., a especulação em torno da existência do aedo, a lenda que afirma ser cego e analfabeto o criador dos dois poemas seminais da literatura - nenhuma destas questões é tratada, pelo menos não diretamente, em Uma viagem à Índia. Nem o fato de Bloom ser um leitor (cf. VI, VIII, 79) e, portanto, distante do tempo em que o canto não era transmitido pelo texto escrito. Aliás, podem ser apenas aparentes as referências às grandes epopeias, presentes no título do livro, no nome do protagonista, na estrutura narrativa. Entretanto, algumas questões inerentes a qualquer épico comparecem ao texto contemporâneo, embora alguns temas desta epopeia sejam mais facilmente encontrados em filmes como Mononcle3 do que n'Os lusíadas.

Não é objetivo deste trabalho discutir se o livro de 2010 é ou não um poema épico. Até Os lusíadas já foram alvo de uma investigação persecutória como essa. Como Jorge de Sena, que tratou "de observar, es- 
truturalmente, o que Camões fez" (SENA, 1970, p. 57), pretendo examinar Uma viagem à Índia a partir das suas semelhanças estruturais e tentar compreendê-la no contraste explícito que prolonga em relação à epopeia camoniana. O título e a estrutura não ocultam alusões evidentes, fazendo da revisitação a lugares que nunca são os mesmos um vasto palimpsesto.

O fascínio pela Índia no imaginário português é indissociável do fato de este ter sido o primeiro espaço da Ásia onde a experiência da Europa geraria aquela (in)familiaridade a que se referiu Freud (2019, p. 47-49): "familiar [heimlich] é uma palavra cujo significado se desenvolveu segundo uma ambivalência, até se fundir, enfim, com seu oposto, o infamiliar [unheimlich]. Infamiliar é, de certa forma, um tipo de familiar". Não é por acaso que o poema nacional português constitui uma reconstrução épica da viagem que tinha por objetivo chegar à Índia. Aportar na simbólica imagem do paraíso perdido ainda significa partir em busca de uma reminiscência e, ao mesmo tempo, retomar " $[\mathrm{u}] \mathrm{m}$ Oriente ao oriente do Oriente" (PESSOA, 2013, p. 59-65), onde até hoje se conjugam o eterno e o imemorável. Por isso, lanço a arriscada hipótese que aponta a Índia não só como o ponto simbólico de chegada do Ocidente, mas como o outro absoluto. Embora nem sempre as referências àquele espaço sejam consequência de experiências de viagem factuais, o regresso à Índia assume o caráter simbólico de uma realidade fantástica que se associa à alegoria como busca de si mesmo, como encontro com o outro que somos nós. Neste aspecto, a Índia do título já não é um lugar sonhado do outro lado do Ocidente, é uma poética fantasmagórica, afinal o outrora viajante é hoje leitor de um mapa de viagens e do seu passado. Se a viagem de avião evoca a sensação de navegação, a terra vista de cima torna-se num mapa atravessado.

Como escreveu Eduardo Lourenço (2013, p. 07), “[t]oda a viagem é viagem à Índia”. Mais do que isso, a Índia recupera o mito de todas as viagens que, ainda hoje, remetem à "estranheza dos primeiros gestos e dos começos iniciais" (DETIENNE, 2000, p. 48, apud RICEEUR, 2011, p. 66). Mais do que narrativas de regresso, a Ítaca ou a Lisboa, a Odisseia, Os lusíadas e Uma viagem à Índia são os épicos de retorno dos seus heróis, são experiências vividas e narradaspor alguém que partiu e regressou. Não importa que mudanças tenham ocorrido nas personagens ou nas cidades, a ela, a elas, sempre se acaba por regressar. Porém, Uma viagem à Índia não é o relato da longa e complicada viagem de Bloom e seu retorno a uma cidade que já nem reconhece como o seu lar. Os dois livros portugueses, com idêntico número de cantos e estâncias, remetem aos gestos dos heróis, ao tempo mítico dos começos, embora o texto contemporâneo não se refira propriamente ao mesmo passado d'Os lusíadas, que canta um herói mais real do que Bloom, de Gonçalo M. Tavares. Nenhum dado da vida desta personagem tem registro concreto,as suas referências são, quase sempre, encontradas na ficção. Portanto, ao contrário do grande épico que serve como exemplo e estrutura, o itinerário de Bloom não consiste em nada além de uma narrativa ficcional. Esta não remete ao percurso de um herói, mas às (des)venturas de um complicated man no século XXI. 
A relação dialética da narração histórica e ficcional é construída de forma diversa. Embora siga, em alguns aspectos, a estrutura do épico camoniano, com uma Proposição em que o narrador elenca aquilo que será e não será matéria do seu canto e um começo de narrativa in medias res, não há Invocação às Musas nem Dedicatória ao Rei. Ou melhor:

Que as ninfas e as musas, e ainda a minha cabeça, me ajudem na escrita, pois escrever assim - epopeias - é exigência de minúcia em animal de grande porte e exigência de grandeza em animais ferozes mas minúsculos. Está sempre do outro lado, portanto.

(VI, VII, 78).

Os planos da Viagem, da História e da Mitologia também são repetidos em Uma viagem à Índia. Entretanto, os possíveis paralelismos entre as duas obras ficam, mais uma vez, pela estrutura, não se estendendo às temáticas. A rota pioneira e desconhecida - portanto, cheia de perigos, reais e imaginários - foi substituída por um mapa traçado, com outro itinerário, outra duração e outros elementos. No lugar da história de Portugal, a narração da vida pessoal de Bloom e da sua família. Os deuses, um dos elementos centrais do épico camoniano, foram afastados no texto contemporâneo a tal ponto que eles "actuam/ como se não existissem, e assim/ não existem, de facto, com extrema eficácia” (VI, I, 22). Bloom pertence a um mundo em que já não há deuses, a um tempo em que Deus está morto (cf. DELEUZE; GUATTARI, 2011, p. 145-146), e que, sem deuses nem heróis, já "[n]ada se dá entre humanos,/ quanto mais entre os deuses e os homens" (VI, VII, 32). Há, de um lado, máquinas, e, do outro, a natureza, que travam uma batalha capaz de pôr à prova os destinos da humanidade.

Distanciadas pelo tempo, estas obras mantêm na pauta do dia os temas da viagem, da guerra e do amor, agora apropriados e, através de aproximações e afastamentos, atualizados no texto do século XXI. Assim como Camões, Gonçalo M. Tavares é capaz de olhar constantemente para o seu tempo e para a antiguidade, colocando o seu complicated man em paralelo com um herói português, grego, irlandês ou americano. Desde a proposição do poema camoniano (cf. Lus., I, 3; II, 44; SARAIVA, 1997, p. 127), fica estabelecida a relação de esquecimento que este confronto com o passado pretende anunciar. Em Uma viagem à Índia, as nove estâncias iniciais do primeiro canto começam por evocar fatos grandiosos do passado e questionam se o nosso século é capaz de oferecer matéria épica, de acordo com as normas clássicas. Curiosamente, o "Não falaremos" treze vezes repetido nessas nove estâncias encontra eco em "Não se encontrará", "Não se fará menção", "Não haverá referência" com que Ernest Hemingway adverte os seus leitores no prefácio de Paris é uma festa. Porém, na estância seguinte, o narrador avisa:

Falaremos da hostilidade que Bloom,

o nosso herói,

revelou em relação ao passado, 
levantando-se e partindo de Lisboa

numa viagem à Índia, em que procurou sabedoria e esquecimento.

$[\ldots](V I, I, 10)$

Esta Proposição contemporânea faz menos menção ao caráter questionável do "valeroso Capitão" (cf. Lus. I, 64; II, 109) da gente portuguesa do que ao seu próprio "projecto pessoal / cheio de perversões" (VI, VII, 86) e, sobretudo, à sua "tragédia familiar":

Mary, a sua amada, por razões não totalmente claras, havia sido assassinada por ordem do seu pai, que Bloom sempre admirara, mas que logo matara em vingança. Sem amor e com sangue paterno nas mãos Bloom havia decidido fazer uma viagem à Índia $(V I, \mathrm{~V}, 86)$.

São estes os dois motivos da sua partida, cujas ações, pontuadas no seu roteiro pelas cidades (e países) que atravessa (Lisboa-Londres-Paris-Alemanha-Viena-Praga-Índia-Paris-Lisboa), parecem apontar para uma dimensão universal, repetindo temáticas presentes em outros livros do autor, como o mundo pós-holocausto e a natureza enquanto contraponto entre a religião e a industrialização, esbarrando numa narrativa alegórica que discute as noções de civilização e barbárie no mundo contemporâneo. Essa narrativa, que repete uma estrutura épica e reúne muita matéria antiépica, acaba por ser um livro contraditório, ainda que algumas passagens possam ser relacionadas a episódios d'Os lusíadas. As suas contrariedades fazem parte de uma retórica sobre a realidade do seu tempo e resultam num texto autônomo e, em muitos aspectos, distante daquele que lhe serviu de base. Apesar de o número de cantos e de estrofes e o destino da viagem serem os mesmos, se comparados a Os lusíadas, a métrica decassilábica das oitavas e as rimas são suprimidas num livro que não trata de uma demanda grandiosa. A grandiloquência aqui é de outra ordem, talvez por já não haver espaço, no nosso tempo, para o mesmo sentido de heroicidade de há cinco séculos. Assim, o percurso de um anti-herói é traçado num livro cujo narrador, que reflete sobre os bastidores da criação literária, parece ter consciência da sua ficcionalidade:

Diga-se ainda (e perdoe-se mais este desvio

- serão tantos, meu caro, prepara-te),

diga-se ainda que as discussões universais dos homens são sempre discussões particulares. [...]

$(V I, I, 33)$

Num movimento de ruptura, o autor se aproxima da epopeia camoniana ao reavaliar a consciência do estatuto ficcional, revisitar o cânone e, repetindo a sua estrutura, questionar outros elementos do texto quinhentista presentes no século XXI. Neste seguimento, é como fantasmagoria que a Índia é apropriada, revisitada e conservada viva na sua função mística - 
já que "a Europa não tem parte mística" (VI, V, 65) - pelo texto de Gonçalo M. Tavares, que não celebra as Índias que houve, nem as que não havia nem as que podia ter havido. Uma viagem à Índia é uma viagem mental que atravessa um fantasma antigo, o da viagem icônica repetida num mundo que a transformou em imagem anacrônica. Nesta espécie de peregrinação da alma para a qual se parte numa jornada interior, o itinerário desenhado por uma geografia real confere paradoxalmente atualidade e ancestralidade ao mesmo lugar das evocações clássicas. Agora extremamente contemporânea, a digressão para a Índia é feita de dois tempos e, por isso, indissociável de uma ideia de coletividade: se Bloom, "europeu e português" (VI, VIII, 71), chega à Índia, ele é todo um povo que simbolicamente chega ao seu destino. Destes dois tempos surge um ponto de passagem entre o texto quinhentista e um conjunto de argumentos centrados no presente. Dos palimpsestos do cânone ficcional português surge uma (contra)epopeia, em muitos aspectos, crítica e irônica daquela que ainda constitui a viagem fundamental. Mas, a revisitação de Gonçalo M. Tavares não descreve apenas a vida de Bloom. Esta viagem é, a um só tempo, individual e coletiva, do passado e do presente, real e onírica, de Bloom e dos gloriosos conquistadores ironizados pela narrativa.

Uma viagem à Índia desenha um roteiro íntimo de uma longa e lenta digressão. Este mapa de releituras oferece não só o desafio de se confrontar consigo mesmo enquanto "peregrino-turista" (LOURENÇO, 2013, p. 11) perdido no século XXI, mas também o de se perder no labirinto de si mesmo. O modo como o narrador lança um dos objetivos da viagem - o de encontrar um "tédio surpreendente" (VI, I, 64) - acaba por advertir para a impossibilidade desse mesmo objetivo num tempo já sem lugar para o espanto tantas vezes repetido naOdisseia, seja porque "[e] m todo o mundo o mundo é mundo" (VI, IX, 15), seja porque um personagem "europeu e português" (VI, VIII, 71) do século XXI já esteve na Índia sem nunca ter lá estado. É na Índia, aliás, que Bloom se dá conta de que "dentro do homem e em cima do mundo,/ tudo há, e nada espanta" (VI, VIII, 62). Através de um repetido exercício de memória, é possível estabelecer a comparação da sua viagem à Índia com Os lusíadas, com as viagens inaugurais da literatura e, mais uma vez, com “Opiário”, de Álvaro de Campos: "Pra que fui visitar a Índia que há/ Se não há Índia senão a alma em mim?” (PESSOA, 2013, p. 59-65).

Muitas vezes, a experiência da Índia acaba por revelar outra demanda, que não se desprende da ideia de uma procura individual, seja essa procura uma fuga ou uma descoberta interior, seja ela metonimicamente coletiva, uma forma de retomar o mote de Campos, que, analogamente, "Perten[cia] a um género de portugueses/ Que depois de estar a Índia descoberta/ Fic[ou] sem trabalho" (PESSOA, 2013, p. 59-65). De fato, essa leitura pode sugerir que Uma viagem à Índia celebra mais o "Opiário" do que Os lusíadas. Isto porque Gonçalo $\mathrm{M}$. Tavares não só retoma a ideia de um sonho extinto - que apenas pode ser revisitado através de um elaborado 
exercício de memória -, como a sua intertextualidade coincide com a ideia de um exílio num território tão seguro quanto o passado. A revisitação de um imaginário fundamental não serve, porém, "para acalentarmos ou recuperarmos o passado (ao final, não fazemos nem um, nem outro), mas para adiarmos a chegada do presente - em outras palavras, para retardarmos a passagem do tempo" (BRODSKY, 2016, p. 29).

No poema "Passage to India", de Leaves of grass (1855), escrito por Walt Whitman, o passado também aparece simbolicamente como o berço da humanidade, o mito das origens em que "[c]ivilização e astronomia não caminham lado a lado" (VI, VII, 65). Mas, afinal, “[o] que é o passado? Isto: tempo que cada vez ocupa/ menos espaço, e tal facto é visível na mala de Bloom" (VI, VIII, 2). Esta viagem não tem outro destino: o presente "ocupa todo o espaço que nos rodeia. Porém, deste/ latifúndio que é o tempo neste minuto, amanhã pouco/ restará” (VI, VIII, 2). Assim como Eduardo Lourenço afirma no prefácio à obra de Gonçalo $M$. Tavares que "todas as viagens são sempre um regresso ao passado de onde nunca saímos" (2010, p. 11), à viagem de Bloom importa menos o ponto de chegada do que o seu itinerário, que se propõea buscar "sabedoria/ e esquecimento", quiçá outra humanidade na nossa estranha condição. Todas essas dimensões se conjugam de forma extraordinária numa única alegoria, que é a da viagem como procura por si mesmo, uma procura de vertente pessoal e universal que confere ao texto uma potência transtemporal e transficcional, tornando-o num ponto para onde convergem diferentes referências hiperliterárias.

No entanto, o mito da Índia espiritual continua a ser o mais recorrente neste imaginário fundamental. A viagem ao Oriente impulsionada pela possibilidade de encontrar uma parte sábia e mística que a Europa nunca teve $(V I, V, 65)$ materializa-se através do encontro com Shankra, um "sábio" que "aprendera/ com as árvores a ser velho" (VI, VII, 58) e que, portanto, poderia ensinar algo àquele homem que "anseia demasiado pela sabedoria" (VI, VIII, 46) e busca um antídoto contra o seu "inferno explícito/ e localizado" (VI, VII, 63). Ao contrário disso, a expectativa gerada por esse encontro é desiludida, e Bloom percebe, como refere Eduardo Lourenço, “que os seus 'gurus' são vulgares e suspeitos vendedores de ilusões como todos os outros" (2010, p. 16). Refutando os pressupostos de Bloom, que "procurará o impossível:/ encontrar a sabedoria enquanto foge;/ fugir enquanto aprende" (VI, I, 39), a sua viagem à Índia, como descobre mais tarde, acaba por não corresponder à "Proposição" que havia estabelecido. Recordo, a este propósito, "uma forma de pensamento para lidar com oestrangeiro" (2007, p. 80) amplamente estudada por Edward Said: "O Orientalismo constituía em última análise uma visão política da realidade, cuja estrutura promovia a diferença entre o familiar (a Europa, o Ocidente, 'nós') e o estranho (o Oriente, o Leste, 'eles')" (2007, p. 78). Mas, o estranho é tanto o Unheimliche freudiano quanto o desassossego pessoano materializado neste outro lado, quer seja o Oriente, quer seja o passa- 
do, inevitavelmente inalcançável, inevitavelmente outro. Aqui, entretanto, o outro também somos nós, cada um "inseparável da sua maldade": "[d]e facto, Bloom já o sabe há muito:/ somos inseparáveis do nosso pior" (VI, VIII, 84). E porque uma das coisas que procura é a sabedoria, Bloom, na Índia, conhece um sábio. Cada um estrangeiro em relação ao outro, Bloom encontra Shankra, cuja

[...] fachada sábia revela, então, pouco a pouco o que esconde.

Bloom está na verdade diante de um ladrão.

De livros, muito bem, mas ladrão

(VI, VIII, 83).

Neste sentido, a viagem à Índia é menos a travessia de um espaço físico que uma experiência transfiguradora ou um encontro com a viagem anterior à qual alude. Em todo o seu percurso, as ideias de viagem e de peregrinação mental parecem confundir-se. E, assim,

Bloom pensou: viajei tanto e tanto viajei para agora terminar em negócios bibliográficos. Pensava (pensa Bloom) que a sabedoria não tinha número de páginas, mas enganei-me. [...]

(VI, VIII, 78)

A este nível, o da intertextualidade ou da revisitação da mitologia literária do Ocidente através de uma série de textos do nosso imaginário de leitores, esta obra de Gonçalo M. Tavares se revela paradigmática na medida em que consiste em uma viagem declaradamente ficcional, mental e que, portanto, celebra o pensamento numa narrativa que desconstrói o cânone da viagem, reinventando o conceito e a forma de epopeia.

Quando Bloom regressa ao ponto de partida, e "Lisboa [o] recebe [] sem comoção" (VI, X, 148), talvez já não seja o mesmo que partiu para um "país tão espiritual" (VI, IV, 88) à procura do "Espírito" (VI, X, 149) e "encontrou a matéria que já conhecia" (VI, X, 149). Perdido por ruas familiares, Bloom pensa numa solução tão clara e violenta quanto "a suprema e melhor garantia de liberdade humana” (ARENDT, 2016, p. 483): “[h]á várias maneiras de um corpo se matar, / e cair do alto sobre a água é uma delas" (VI, X, 155). Esta atitudeé aqui sugerida como o salto para a água - do rio sob a ponte ou para dentro da água como do útero ou do nada. Como “a lógica / da desgraça é a da queda" (VI, VII, 63), Bloom está mais uma vez nesta iminência, a do salto para a Morte, para o Amor, para o Livro que proporciona a compreensão do seu próprio abismo. À procura de “ $[\mathrm{u}] \mathrm{m}$ tédio surpreendente" (VI, I, 64), Bloom parece, a cada passo, caminhar em direção à queda anunciada no canto IV, mas que pode estar mais próxima de se materializar nas últimas estâncias do livro.

Contudo, o Amor é não só a "única velharia que chegou intacta / ao estúpido século xxi” (VI, IX, 32), mas a única "fonte de extração camoniana para a hipótese de concerto do sujeito no mundo": "o desejo de que o 
Amor individual ('lírico') seja o terceiro termo justo, a partir da interação tensa entre dois estados, que se complementam quase sempre por figuras de exclusão, como, por exemplo, a imagem do 'amor ardente'" (SILVEIRA, 2008 , p.17). Entre o fall in love e o mourir d'amour, Bloom regressa ao ponto de partida, "Lisboa [o] recebe [tão] sem comoção" (VI, X, 148), quanto quando chegara à Índia:

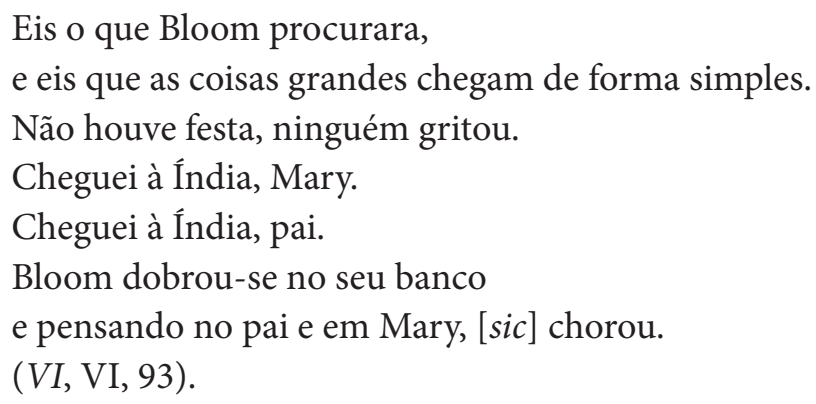

No entanto, a narrativa não acaba aqui. Falta falar da última tentativa para "a hipótese de concerto do sujeito no mundo", falta falar de uma mulher que lhe aparece justamente quando tenta o suicídio "em cima de uma ponte alta" (VI, X, 155). Este último encontro suspende o salto de Bloom quando " $[\mathrm{u}] \mathrm{ma}$ mulher, entretanto, aproxima-se. / Bloom vira a cabeça; é uma mulher bonita, que sorri" (VI, X, 155). Mas "Bloom encolhe os / ombros. / [...] / Ele aproxima-se da mulher e o mundo prossegue, / mas nada que aconteça poderá impedir o definitivo tédio de / Boom, o nosso herói” (VI, X, 156). A viagem de Bloom termina suspensa numa ponte da qual não se pode entrever se ele escolhe a libertação ou a encruzilhada, a possibilidade de um novo amor ou a fatalidade de tudo continuar a se mover sem comoção. Assim como boa parte da lírica camoniana, todo o texto de Gonçalo M. Tavares é uma jornada em busca de sentido para as contradições daquilo que no amor é humano. Mais que "europeu e português" (VI, VIII, 71), Bloom é um complicated man, sempre no limite perigoso entre o fall in love e o mourir d'amour, que permanece incerto ${ }^{6}$ porque "unilateral", já que "o seu único lado/ era este: o lado virado para Mary" (VI, III, 119).

\section{REFERÊNCIAS BIBLIOGRÁFICAS}

ARENDT, Hannah. Escritos judaicos. São Paulo: Amarilys, 2016.

BRODSKY, Joseph. Sobre o exílio. Belo Horizonte: Editora Âyiné, 2016.

CAMÕES, Luís de. Os lusíadas. Ed. E. P. Ramos. Porto: Porto Editora, 1978.

.Lírica de Luís de Camões. Apresentação crítica, seleção, notas e glossário de Maria Vitalina Leal de Matos. Alfragide: Editorial Caminho, 2012.

DELEUZE, Gilles; GUATTARI, Félix. O anti-Édipo: capitalismo e esquizofrenia 1. 2a ed. Trad. Luiz B. L. Orlandi. São Paulo: Editora 34, 2011. 
FREUD, Sigmund. O infamiliar/ Das Unheimliche seguido de O homem da areia, de E.T.A. Hoffmann. Ed. Bilingue. Belo Horizonte: Autêntica Editora, 2019.

GALINDO, Caetano. Em tradução (feminismo). Blog da Companhia. 28 maio 2019. Disponível em: http://www.blogdacompanhia.com.br/conteudos/visualizar/Em-traducao-feminismo?fbclid=IwAR2\%2Wx68yqf0 C1s-CWfBg73ozXPG16gyFUUsFT4PWtXtvbLTF11Znc7GGpD0. Acesso em: 10 jun. 2019.

HEMINGWAY, Ernest. Paris é uma festa. 24a ed. Trad. Ênio Silveira. Rio de Janeiro: Bertrand Brasil, 2018.

HOMER, The odyssey. Translatedby Emily Wilson. New York; London: W. W. Norton \&Company, 2018.

HOMERO, Odisseia. Trad. Frederico Lourenço. São Paulo: PenguinClassics Companhia das Letras, 2011.

LOURENÇO, Eduardo. Uma viagem no coração do caos. In:TAVARES, Gonçalo M. Uma viagem à Índia: melancolia contemporânea (um itineráio). Lisboa: Caminho, 2010, p.05-16.

. A dupla viagem.In: FARIA, Almeida. O murmúrio do mundo: a Índia revisitada. Rio de Janeiro: Tinta-da-china Brasil, 2013, p. 07-16.

PESSOA, Fernando. Poesia de Álvaro de Campos. Lisboa: Assírio \& Alvim, 2013.

RICCEUR, Paul. Sobre a tradução. Belo Horizonte: Editora UFMG, 2011.

SAID, Edward. Orientalismo: o Oriente como invenção do Ocidente. São Paulo: Companhia das Letras, 2007.

SARAIVA, António José. Luís de Camões. Lisboa: Gradiva, 1997.

SENA, Jorge de. A estrutura de Os lusíadas e outros estudos camonianos e de poesia peninsular do século XVI. Lisboa: Portugália Editora, 1970.

SILVEIRA, Jorge Fernandes da. O Tejo é um rio controverso:António José Saraiva contra Luís Vaz de Camões. Rio de Janeiro: 7Letras, 2008.

TAVARES, Gonçalo M. Uma viagem à Índia: melancolia contemporânea (um itinerário). Prefácio Eduardo Lourenço. Lisboa: Caminho, 2010.

WHITMAN, Walt. Song ofmyself. The Walt Whitman Archive. Disponível em: <https://whitmanarchive.org/published/LG/1891/poems/239>. Acesso em: 10 jun. 2019. 


\section{NOTAS}

1 Pesquisadora de pós-doutorado no Programa de Pós-Graduação em Letras Vernáculas da Universidade Federal do Rio de Janeiro com bolsa FAPERJ de Pós-Doutorado Nota 10.

2 As referências a Uma viagem à Índia: melancolia contemporânea (um itinerário) são indicadas no corpo do texto através das iniciais VI, seguidas do número do canto e da estrofe.

3 Mon oncle. Direção: Jacques Tati. França/ Itália, 1958.

4 Cf. SILVEIRA, 2008, p. 119-120, sobre a biografia obscura de Vasco da Gama apresentada como "um nada ordinário colonizador sanguinário e incendiário" no "polêmico" livro de Sanjay Subrahmanyam: A carreira e a lenda de Vasco da Gama. Lisboa: Comissão Nacional para as Comemorações dos Descobrimentos Portugueses, 1998.

5 Disponível em: <https://whitmanarchive.org/published/LG/1891/poems/239>. Acesso em: 10jun. 2019.

6 Cf. Soneto “Tanto de meu estado me acho incerto,". 